\title{
Indian Journal of
}

\section{CRITICAL CARE MEDICINE}

Peer-reviewed, Official Publication of INDIAN SOCIETY OF CRITICAL CARE MEDICINE

Indian Journal of Critical Care

Medicine is indexed/listed with

Excerpta Medica/EMBASE, CAB

Abstracts, Global Health, CINAHL

Database, Cumulative Index to

Nursing and Allied Health Litera-

ture, MANTIS, Health \& Wellness

Research Center, Health Refer-

ence Center Academic, InfoTrac

One File, Expanded Academic

ASAP, electronic databases of

EBSCO, and Indian Science

Abstracts.

Indian Journal of Critical Care

Medicine is published quarterly

(in March, June, September and

December).

The information and opinions presented in Indian Journal of Critical

Care Medicine reflect the views of the authors and not of the Society or the Editorial Board. Acceptance does not constitute endorsement by ISCCM.

All the rights are reserved. Apart from any fair dealing for the purposes of research or private study, or criticism or review, no part of the publication can be reproduced, stored, or transmitted, in any form or by any means, without the prior permission.

Indian Journal of Critical Care Medicine and/or its publisher cannot be held responsible for errors or for any consequences arising from the use of the information contained in this journal. The appearance of advertising or product information in the various sections in the journal does not constitute an endorsement or approval by the journal and/or its publisher of the quality or value of the said product or of claims made for it by its manufacturer.

The Journal is printed on acid free paper.

EDITORIAL OFFICE

Dr. Sandhya Talekar

Chief Editor, IJCCM

Shree Medical Foundation, Prayag

Hospital, 1247, Deccan Gymkhana,

Pune 411004, India.

Tel: $91205532812 / 5532490$

Fax: 91205534448

E-mail: editor@ijccm.org

\section{PUBLISHED BY}

Medknow Publications

A-108/109, Kanara Business Center

Off Link Rd, Ghatkopar (E),

Mumbai - 400075, India.

Phone: 91-22-6649 1818 / 1816,

E-mail: publishing@medknow.com

\section{WEBSITES}

www.ijccm.org

www.bioline.org.br/cm

www.journalonweb.com/ijccm

\section{CHIEF EDITOR}

Dr. Sandhya Talekar

sandhya_talekar@yahoo.com

\section{EXECUTIVE EDITOR}

Dr. Shirish Prayag

shirishprayag@gmail.com

\section{ASSISTANT EDITORS}

Dr. R. K. Mani

rkmjs@vsnl.net

Dr. J. V. Divatia

jdivatia@vsnl.com
Dr. Farhad Kapadia

fnkapadia@gmail.com

\section{MEMBERS OF EDITORIAL BOARD}

Dr. S. S. lyer (Pune)

s_iyer@vsnl.com

Dr. Atul Kulkarni (Mumbai)

kaivalyaak@yahoo.co.in
Dr. N. Ramakrishnan (Chennai)

icudoctor@gmail.com

Dr. Lalitha Pillai (Pune)

lalithapillai29@rediffmail.com

\section{PEDIATRIC SECTION}

Dr. K. Chugh

gangaram@giasdl01.vsnl.net.in

Dr. Sunit Singhi (Chandigarh)

drsinghi@glide.net.in
Dr. Pravin Khilnani (New Delhi) praveenk@nde.vsnl.net.in

Dr. Soonu Udani (Mumbai) drudani@hotmail.com

\section{NATIONAL ADVISORY BOARD}
Dr. M. B. Agarwal
Dr. H. S. Ballal
Dr. Dilip Karnad
Dr. Ram Rajagopalan
Dr. Manimala S. Rao
Dr. Subhash Todi
Dr. F. E. Udwadia
Dr. R. S. Wadia

\section{INTERNATIONAL ADVISORY BOARD}
Dr. David Baker (France)
Dr. Geoffrey Dobb (Australia)
Dr. Ken Hillman
Dr. Mitchell Levy (USA)
Dr. Michael Parr (Australia)
Dr. Ian Seppelt (Australia)

Dr. Laurent Brochard (France)

Dr. K. Guntupalli (USA)

Dr. Roop Kishen (UK)

Dr. Ramesh Nagappan (Australia)

Dr. Gilbert Park (UK)

Dr. J. L.Vincent (Belgium) 


\title{
Indian Journal of \\ CRITICAL CARE MEDICINE
}

\section{Official publication of Indian Society of Critical Care Medicine}

Oct-Dec 2007

Volume 11, Issue 4

\author{
C ONTENTS
}

Editorials

Original Articles

Review Article

Case Reports
It is not just the work - It is also the words

- Murali Ramaswam 169

The ideal transfusion trigger in critically ill patients

- M. B. Agarwal 173

An increase in weight worsens the respiratory state and leads to intensive care unit re-admission

- Yoshinori Matsuoka, Akinori Zaitsu 176

A prospective cohort study on anemia and blood transfusion in critically ill patients

- Naveen Manchal, S. Jayaram 182

Comparison of norepinephrine and dopamine in the management of septic shock using impedance cardiography

- Sharad K. Mathur, Rajiv Dhunna, Arpan Chakraborty 186

Determination of intravascular volume status in critically ill patients using portable chest X-rays: Measurement of the vascular pedicle width

- Nawal Salahuddin, M. Aslam, Ishtiaq Chishti, Shehla Siddiqui 192

Role of physiotherapists in intensive care units of India: A multicenter survey

- Jithendra A. Kumar, Arun G. Maiya, Daphne Pereira 198

Postoperative pain and its management

- Sona Chaturvedi, Amit Chaturvedi 204

Rhabdomyolysis due to hair dye poisoning: An emerging threat

- Krishnaswamy Sampathkumar, Yesudas Santhakumari Sooraj, Rajappannair Prabha Ajeshkumar, Amol Ramesh Mahaldar, Ramakrishnan Muthiah

Severe hyperkalemia with normal electrocardiogram

- Sanjay Sharma, Harish Gupta, Meena Ghosh, Anantanarayan Padmanabhan 215

International Conference Calendar 218

Author Index - 2007 $000 ? ?$

Title Index - 2007 


\title{
Role of physiotherapists in intensive care units of India: A multicenter survey
}

\author{
Jithendra A. Kumar, Arun G. Maiya*, Daphne Pereira*
}

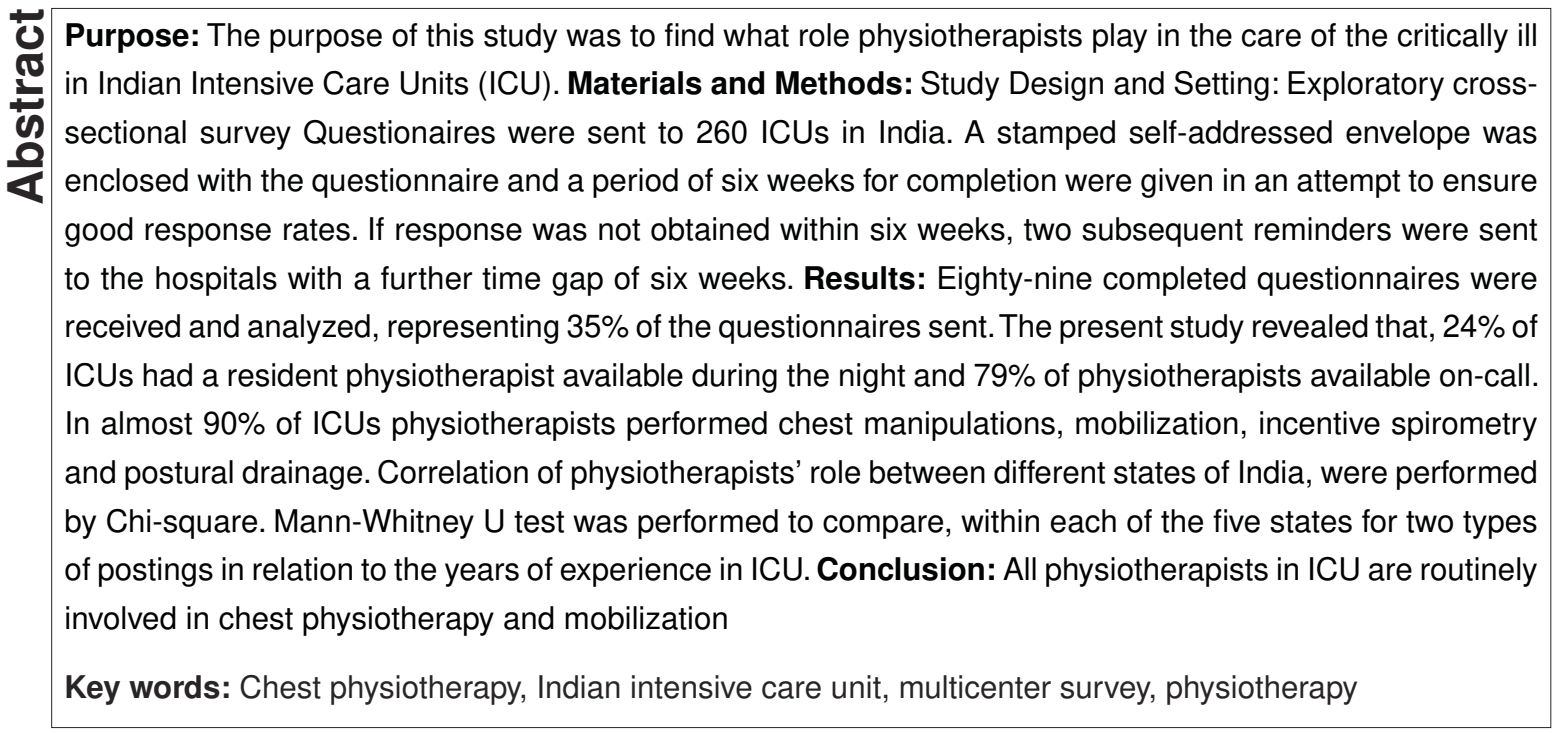

\section{Introduction}

"An intensive care unit (ICU) is a specially staffed and equipped hospital ward dedicated to the management of patients with life-threatening illnesses, injuries or complications" (Oh, 1998). [1] Throughout the course of ICU development, the role and responsibility of the physiotherapist has been poorly defined. In an ICU consensus conference in 1983, authors clarified the roles of physicians and nurses but not physiotherapists. In regard to physiotherapists it was simply mentioned that they should be included in the ICU team and

From:

Department of Physiotherapy, Center for Basic Sciences, K.M.C, Bejai, Mangalore - 575 004, Karnataka, *MCOAHS, Manipal, Karnataka, India

\section{Correspondence:}

Dr. Jithendra A Kumar, Department of Physiotherapy, Center for Basic Sciences, K.M.C, Bejai, Mangalore - 575 004, Karnataka, India.

E-mail: jithendra21@rediffmail.com should be involved in any continuous training programs. Consequently, there is little uniformity in physiotherapy training or duties, with considerable variation between and sometimes within countries. ${ }^{[2]}$ Although a wide variety of literature is available about the roles of nurses and physicians in the ICU, the role of physiotherapists has received comparatively little attention and remains largely undefined and variable across sites. ${ }^{[3,4]}$

Physiotherapists in the ICU are part of a multidisciplinary team involved in the treatment of critically ill patients. Physiotherapists liase closely with medical, nursing and other allied health professionals regarding patient condition, progression and treatment plans. ${ }^{[5]}$

In order to understand the role of physiotherapists, two things must be considered, namely the degree to 
which specialist physiotherapy services are available in the ICU and the specific tasks that are performed by physiotherapists in the ICU. Literature regarding the staffing levels and the availability of physiotherapists in the ICU is rare.

In a study of European ICUs, Norrenberg and Vincent ${ }^{[6]}$ found that one quarter of the ICUs did not have exclusive physiotherapists for ICUs and two thirds had no physiotherapist available after hours, suggesting that the inclusion of physiotherapy within the ICU multidisciplinary team may not be firmly established.

The precise role that physiotherapists play in the ICU varies considerably from one unit to the next, depending on factors such as the country in which the ICU is located, local tradition, staffing levels, training and expertise. ${ }^{[7]}$ The referral process is one example of this variation, in some ICU's, physiotherapists assess all patients, whereas in other ICU's patients are seen only after referral from medical staff. ${ }^{[7]}$ Despite the emphasis on multidisciplinary team, the lack of role definition has resulted in many specialist physiotherapy services being subsumed by other professional groups, mostly nursing staff. The lack of strong evidence base to support the role of physiotherapists in the ICU has undermined the importance of providing specialist physiotherapists.

In intensive care units, physiotherapists are involved in the prevention and treatment of pulmonary, circulatory, musculoskeletal system and integumentary complications, by regular chest physiotherapy, graded mobilization and proper positioning of patients. The role of physiotherapists as stated by Kathy Stiller, ${ }^{[8]}$ in the ICU are positioning, mobilization, manual hyperinflation, percussion, vibration, coughing, suctioning, various breathing exercises and limb exercises. Colin F. Mackenzie ${ }^{[9]}$ stated the role of physiotherapists in ICU as positioning, postural drainage, percussion, vibration, manual lung inflation, coughing, tracheal suctioning, breathing exercises, patient mobilization and application of aerosol, humidification, incentive spirometry, forced expiratory techniques, bronchodilators and mucolytic agents.

There is no available information on the role of physiotherapists in ICUs in India. The purpose of this study was to find what role physiotherapists play in the care of the critically ill in Indian ICU.

\section{Materials and Methods}

\section{Study design}

\section{Exploratory cross sectional survey.}

\section{Participants}

Physiotherapists who are currently working in ICU with two years of working experience were requested to fill the questionnaire.

\section{Procedure}

The study was reviewed and approved by the institutional ethical committee, Manipal College of Allied Health Sciences (MCOAHS), Manipal Academy of Higher Education (MAHE). The lists of hospitals were obtained from Indian Association of Physiotherapists (IAP) and Medical Council of India (MCl) websites. A total of 500 hospitals were identified. In India, both modern medicine and traditional systems of medical practice are well established. In this study the traditional systems of medical practices like Unani, Ayurveda, homeopathy and dental colleges were excluded and a total of 260 hospitals from the above mentioned websites were included in the study.

Survey was done by the questionnaire and pilot study was conducted at Kasturba Medical College Hospital, Manipal and Kasturba Medical College Hospital, Mangalore. Physiotherapists involved in ICU were given the questionnaire, experts in the field of cardiorespiratory physiotherapy with 10 years of working experience were consulted for their comments on the questionnaire design, structure and content and a final questionnaire was prepared. The questionnaire covers details of the hospital (number of beds in hospital and ICU beds), therapist profile (qualification, experience) and role of physiotherapists (chest manipulation, positioning, mobilization, breathing exercise, postural drainage and advanced physiotherapeutic techniques) in ICU and several other questions were incorporated to elicit the information about physiotherapists awareness to ICU.

Questionnaires were posted to the Head of the department of physiotherapy of the hospitals selected. As per the inclusion criteria, physiotherapists who are currently working in ICU with two years of working experience, were requested to fill the questionnaire.

A covering letter was included explaining the purpose of 
the questionnaire, identifying the researcher and assuring confidentiality.

A stamped self-addressed envelope was included with the questionnaire and a period of six weeks for completion was given in an attempt to ensure good response rates. If response was not obtained within the stipulated time period, two subsequent reminders were sent to the hospitals with a time gap of six weeks for the first reminder and four weeks for the second reminder. Non-respondents were excluded from the study after the second reminder.

\section{Data analysis}

Questionnaire contents were statistically analyzed by SPSS (V. 10) software. Data was summarized using percentages. Chi-square was performed for correlations of physiotherapists' role between states, Mann-Whitney $U$ test was performed to compare years of experience of physiotherapists in ICU with their postings in ICU, KruskalWallis test was performed to compare physiotherapists' years of experience in ICU within different states.

\section{Results}

A total of 89 completed questionnaires were received out of 260 (35\% response rate) with the largest response from Karnataka, Maharashatra, Andhra Pradesh, Delhi and Tamil Nadu in descending order [Table 1]. Out of 89 questionnaires received, 23 (26\%) were from hospitals with more than 500 to 1000 beds. Forty (45\%) respondents were from hospitals with 10 to 20 beds in ICU. Majority of the respondents (59\%) working in ICU were postgraduate qualified physiotherapists [Table 2].

Twenty four percent of ICUs had a resident physiotherapist available during the night and $79 \%$ of physiotherapists available on call. Many respondents, $78 \%$, reported their posting to be on rotation basis rather than on permanent basis.

The role of physiotherapists in ICUs is presented in [Figure 1]. Ninety one percent respondents reported to be involved in chest manipulation, $100 \%$ in mobilization, $100 \%$ in breathing exercises, $94 \%$ incentive spirometry, $98 \%$ in postural drainage, $95 \%$ in assisted coughing and huffing.

The respondents reported that $(55 \%)$ of the referral
Table 1: State-wise response to the questionnaire

\begin{tabular}{lccc}
\hline State & $\begin{array}{c}\text { Number } \\
\text { sent }\end{array}$ & $\begin{array}{c}\text { Number } \\
\text { received }\end{array}$ & $\begin{array}{c}\text { Proportion of } \\
\text { response (\%) }\end{array}$ \\
Andhra Pradesh & 42 & 14 & 15.73 \\
Assam & 3 & 0 & 0 \\
Bihar & 15 & 0 & 0 \\
Chandigarh & 2 & 0 & 0 \\
Delhi & 21 & 12 & 13.48 \\
Goa & 2 & 1 & 1.12 \\
Himachal Pradesh & 1 & 0 & 0 \\
Jammu and Kashmir & 4 & 1 & 1.12 \\
Gujarat & 12 & 3 & 3.37 \\
Karnataka & 54 & 24 & 26.96 \\
Kerala & 6 & 1 & 1.12 \\
Maharashtra & 31 & 15 & 16.85 \\
Orissa & 3 & 1 & 1.12 \\
Pondicherry & 2 & 1 & 1.12 \\
Punjab & 7 & 2 & 2.24 \\
Rajasthan & 3 & 1 & 1.12 \\
Tamilnadu & 37 & 10 & 11.23 \\
Uttar Pradesh & 8 & 1 & 1.12 \\
West Bengal & 2 & 1 & 1.12 \\
Madhya Pradesh & 5 & 1 & 1.12 \\
\hline
\end{tabular}

\begin{tabular}{lcc}
\hline \multicolumn{3}{c}{ Table 2: Hospital and patient demographic data } \\
\hline Hospital bed distribution & $\mathbf{n}$ (Number) & Percentage \\
$<100$ beds & 8 & 8.9 \\
$100-200$ beds & 10 & 11.23 \\
$201-300$ beds & 10 & 11.23 \\
$301-400$ beds & 9 & 10.11 \\
$401-500$ beds & 12 & 13.48 \\
$>500-1000$ beds & 23 & 25.84 \\
$>1000$ beds & 17 & 19.1 \\
ICU bed distribution & & \\
<10 beds & 24 & 26.96 \\
$10-20$ beds & 40 & 44.94 \\
$21-30$ beds & 16 & 17.97 \\
$31-40$ beds & 5 & 5.95 \\
$41-50$ beds & 1 & 1.12 \\
$>50-100$ beds & 3 & 3.37 \\
Type of ICU & & \\
Multidisciplinary & 64 & 71.91 \\
Neuro & 34 & 38.2 \\
Cardiac & 42 & 47.19 \\
Post-operative & 40 & 44.94 \\
Neonatal & 32 & 35.95 \\
Burns & 18 & 20.22 \\
Nephro & 16 & 17.97 \\
Qualification of the physiotherapists & & \\
Diploma & 1 & 1.12 \\
Bachelors & 35 & 39.32 \\
Masters & 52 & 58.42 \\
Ph D & 1 & 1.12 \\
Teaching/non-Teaching & & \\
Teaching & 69 & 77.52 \\
Non-teaching & 20 & 22.47 \\
Experience as physiotherapist & & \\
1-5 years & 47 & 52.8 \\
6-10 years & 22 & 24.71 \\
$>10-20$ years & 17 & 19.1 \\
$>20$ years & 3 & 3.37 \\
\hline
\end{tabular}

system in the ICUs is by physician. Overall response rate of the physiotherapists being in setting ventilatory parameters was $10 \%$, with respondents involved in weaning being $18 \%$. 


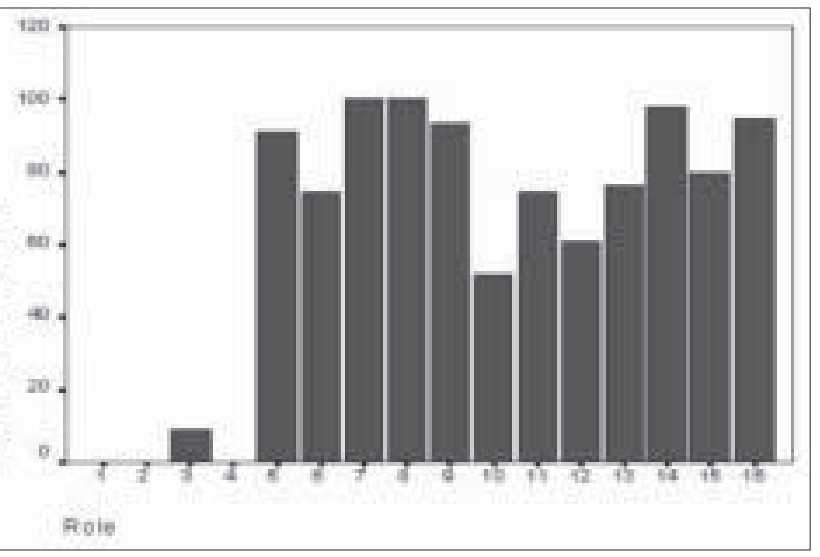

Figure 1: Different role of Physiotherapistss in ICU's of India.

1-Percussion only, 2- Vibration only, 3-Percussion+Vibration,

4- Suctioning only, 5- Chest manipulation (Percussion + vibration + suctioning), 6- Positioning, 7- Mobilization, 8- Breathing exercises, 9- Incentive spirometry, 10-Ambulation of tracheostomy patients in ICU, 11-Ambulation of non-intubated patients in ICU, 12- Counseling 13-Nebulization+ Humidification, 14- Postural drainage, 15- Forced expiratory technique, 16- Assisted coughing and huffing

Correlation of role of physiotherapists between different states of India [Table 3] has been performed by ChiSquare, except ambulation of non-intubated patients, all other parameters were found to be non significant.

Mann-Whitney U test was performed to compare, within each of the five states for two types of postings in relation to the years of experience in ICU [Table 4] and it was found to be insignificant significant. Kruskal-Wallis test was performed to compare between five states for two types of postings with relation to the years of experience [Table 5] and was found to be insignificant.

\section{Discussion}

Remarkably, a dearth of literature exists regarding the role of physiotherapists in intensive care units. In order to understand the role of physiotherapists, two things must be considered, namely the degree to which specialist physiotherapy services are available in the ICU, and the specific tasks that are performed by physiotherapists in the ICU. Literature regarding the staffing levels and availability of physiotherapists in the ICU is rare.

According to the results of our survey, Indian ICU physiotherapists perform both the roles of chest physiotherapy and mobilization. Apart from the roles mentioned in the questionnaire, therapists are also involved in application of non-invasive ventilation, proprioceptive neuromuscular facilitation in respiration, bedsore management, active cycle of breathing techniques and autogenic drainage.

In our study $91 \%$ of the respondents reported to perform chest manipulation (percussion, vibration, suctioning), on comparison with other countries Australian physiotherapists $(79 \%),{ }^{[10]}$ European $(98 \%)^{[6]}$ counterparts.

Therapists in ICU are not only involved in chest physiotherapy techniques, but also reported to have a very active role in mobilization and positioning. Mobilization from our study was found to be $100 \%$, which is on par with Australia (100\%) ${ }^{[10]}$ and Europe (100\%). ${ }^{[6]}$ The above data reveals that therapists from different parts of the country are involved in patient mobilization inside the ICU which focuses on representing early rehabilitation. In, therapeutic positioning was found to be $75 \%$, while it was higher in Australia (100\%) ${ }^{[10]}$ and Europe (90\%). ${ }^{[6]}$

We found on-call physiotherapists available in Indian ICUs were $79 \%$ as compared to elsewhere, Europe $(83 \%),{ }^{[6]}$ Australia $(66 \%)^{[10]}$ and South Africa (96\%). ${ }^{[11]}$

Even though recognition of the need for physiotherapists in ICU is growing world wide, the kind of referral system being practiced in Indian ICUs is physician-based (55\%) rather than being standard treatment. Physiotherapists

\section{Table 3: Correlation of role of physiotherapists between different states of India}

\begin{tabular}{|c|c|c|c|c|c|c|}
\hline & $\begin{array}{c}\text { Andhra Pradesh } \\
n=14\end{array}$ & $\begin{array}{c}\text { Maharashtra } \\
n=15\end{array}$ & $\begin{array}{l}\text { New Delhi } \\
n=12\end{array}$ & $\begin{array}{c}\text { Tamilnadu } \\
n=10\end{array}$ & $\begin{array}{c}\text { Karnataka } \\
n=24\end{array}$ & $\begin{array}{c}\text { Significance } \\
P \text { value }\end{array}$ \\
\hline Chest manipulation & $14(100.0)$ & $15(100.0)$ & $12(100.0)$ & $10(100.0)$ & $24(100.0)$ & 1 \\
\hline Positioning & $13(92.9$ & $14(93.3)$ & $12(100.0)$ & $10(100.0)$ & $23(95.8)$ & 0.817 \\
\hline Limb physiotherapy & $13(92.9)$ & $15(100.0)$ & $12(100.0)$ & $10(100.0)$ & $24(100.0)$ & 0.353 \\
\hline Breathing exercise & $13(92.9)$ & $15(100.0)$ & $12(100.0)$ & $10(100.0)$ & $24(100.0)$ & 0.353 \\
\hline Incentive spirometry & $13(92.9)$ & $15(100.0)$ & $12(100.0)$ & $9(90.0)$ & $23(95.8)$ & 0.658 \\
\hline Ambulationof tracheostomy patient & $7(50.0)$ & $8(53.3)$ & $6(50.0)$ & $7(70.0)$ & $10(41.7)$ & 0.677 \\
\hline Ambulation of non intubated patient & $6(42.9)$ & $13(86.7)$ & $8(66.7)$ & $10(100.0)$ & $19(79.2)$ & 0.013 \\
\hline Postural drainage & $13(92.9)$ & 14 (93.3) & $12(100.0)$ & $10(100.0)$ & $24(100.0)$ & 0.514 \\
\hline Forced expiratory technique & $11(78.6)$ & $11(73.3)$ & 7 (58.3) & $10(100.0)$ & $20(83.3)$ & 0.182 \\
\hline
\end{tabular}

Figures in parentheses indicate percentage 


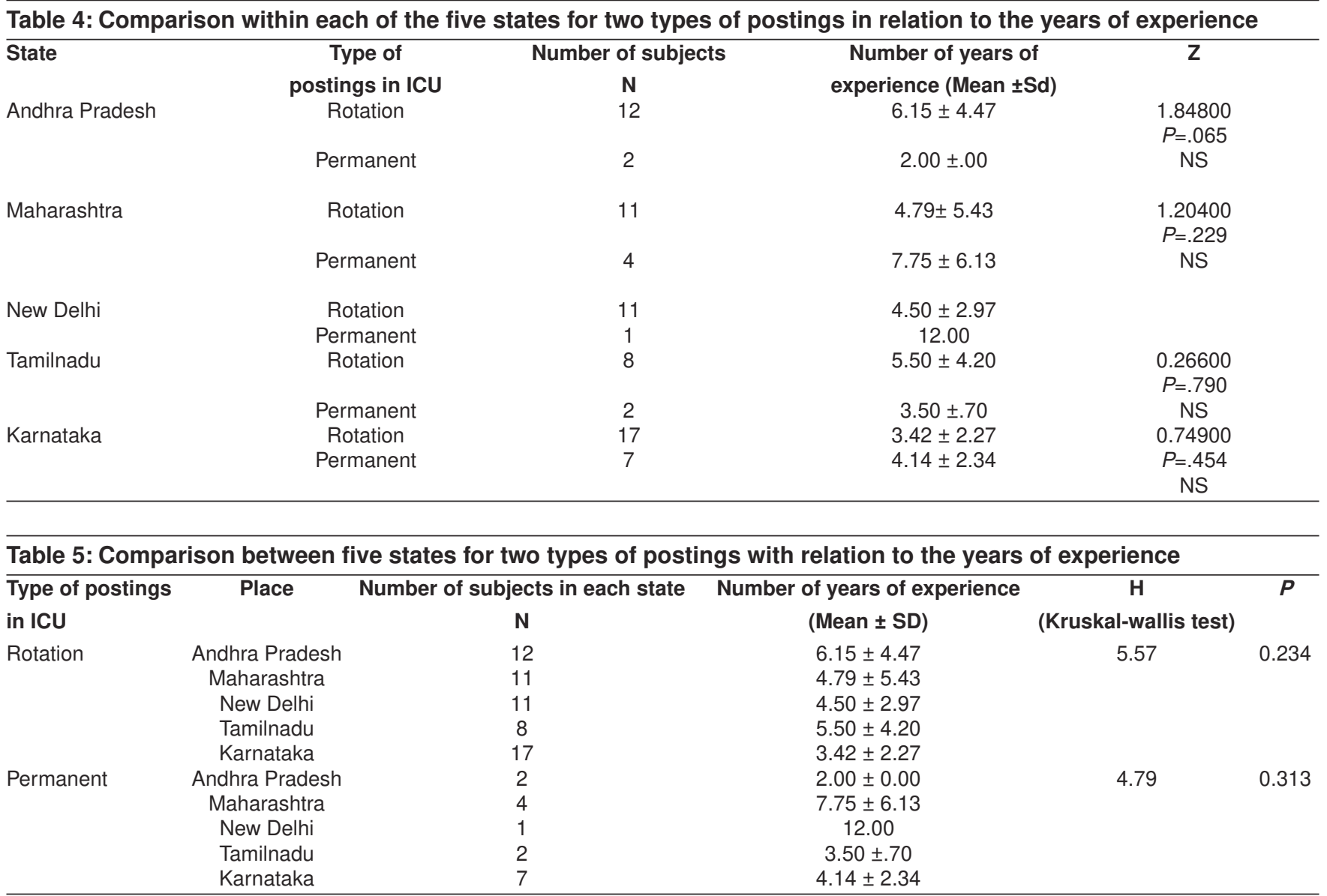

were not found to be involved in setting setting or adjusting ventilatory parameters and weaning, but majority of them were involved in suctioning during extubation and some reported to be a part of the weaning team.

No conclusion could be made between duration of experience of physiotherapists in ICU with postings in ICU and duration of experience with different states.

Future studies should be aimed at identifying probable factors influencing the role of physiotherapists in ICU-like hospital administration policies, inter-professional needs and type of specialized care required.

More number of ICUs should be included in the future studies.

\section{Conclusions}

1. Our study showed that not all patients in Indian ICUs get routine chest physiotherapy as part of their ICU care unless referred by an ICU physician, so physiotherapy should be standard routine management of such patients.
2. All physiotherapists in the ICU are routinely involved in both chest physiotherapy and mobilization.

\section{Acknowledgements}

The study in part has been supported in the form of grant by The Indian Association of Physiotherapists (IAP).

\section{References}

1. Oh TE. Intensive Care Manual. $4^{\text {th }}$ ed. Butterworth- Heinemann Publishers: 1999. p. 3-4.

2. NIH consensus Development Conference on critical care medicine. Crit Care Med 1983;11:466-9.

3. Depasse B, Pauwels D, Somers Y, Vincent JL. A profile of European ICU nursing. Intensive Care Med 1998;24:939-45.

4. Dunn SV, Lawson D, Robertson S, Underwood M, Clark R, Valentine $\mathrm{T}$, et al. The development of competency standards for specialist critical care nurses. J Adv Nurse 2000;31:339-46.

5. ACT Government Health Information. Available from: http://www. health.act.gov.au/c/health.

6. Norrenberg M, Vincent JL. A profile of European intensive care unit physiotherapists. Intensive Care Med 2000;26:988-94. 
7. Jones AY, Hutchinson RC, Oh TE. Chest physiotherapy practice in intensive care units in Australia, the UK and Hong Kong. Physiother Theory Pract 1992;8:39-47.

8. Stiller K. Physiotherapy in intensive care: Towards an evidencebased practice. Chest 2000;118:1801-13.

9. Mackenzie CF, Ciesla N, Imle PC. Chest physiotherapy in Intensive care unit. $2^{\text {nd }}$ ed. Williams and Wilkins: 1989. p. 93-187.

10. Chaboyer W, Elizabeth G, Foster M. Patterns of chest physiotherapy in Australian Intensive Care Units. J Crit Care 2004;19:145-51.

11. Van Aswegen H, Potterton J. A pilot survey of the current scope of practice of South African Physiotherapists in Intensive Care Units. South Afr J Physiother 2000;61:17-21.

\section{Questionnaire}

(Please $\checkmark$ where ever appropriate)

Hospital

1. Name of the state where hospital is located

2. City

3. Number of beds in the hospital

4. Number of beds in largest ICU

5. Hospital - Teaching / Non-teaching

\begin{tabular}{lcc}
\multicolumn{2}{l}{ Equipments used regularly in ICU (in working condition) } \\
Ventilator $\mathrm{Y} / \mathrm{N}$ & Number & \\
ECG monitors & $\mathrm{Y} / \mathrm{N}$ & Number__ \\
Pulse oxymetry & $\mathrm{Y} / \mathrm{N}$ & \\
Oxygen lines & $\mathrm{Y} / \mathrm{N}$ & \\
Central suction lines & $\mathrm{Y} / \mathrm{N}$ & Number___ \\
Mobile suction units & $\mathrm{Y} / \mathrm{N}$ & \\
AMBU & $\mathrm{Y} / \mathrm{N}$ & \\
Type of AMBU & & Number__ \\
HUDSON MAPLESON C & & Fixed \\
Nebuliser & Y / N &
\end{tabular}

\section{Physiotherapist profile}

- Qualification: Diploma (3 yrs) / BPT / MPT/ PhD (Masters and PhD pl. specify the area of specialty)

- Gender: M/F

- Duration of experience as physiotherapist: month/year

- Duration of experience in ICU: month/year

\section{State the area of ICU where you work}

Multi disciplinary ICU Neuro ICU

Cardiac ICU

Neonatal ICU

Nephrology ICU

Postoperative ICU

Burns ICU

Others:
- Do you have night duties - $\mathrm{Y} / \mathrm{N}$

- Do you have rotational postings on holidays - Y/N

Patients seen by you are

On physician referral

On routine assessment

Role of physiotherapist in ICU (State your role in ICU)

Percussion only

Vibration only

Percussion and vibration (chest manipulation)

Suctioning

Chest manipulation and suctioning

Positioning (Supine, side-lying, prone)

Limb physiotherapy

Breathing exercises

Incentive spirometry

Counseling

Ambulating tracheostomy patients with $\mathrm{AMBU}$ in ICU

Ambulating non intubated patients in ICU

Aerosol therapy

Nebulisation

Oxygen therapy

Postural drainage

Forced expiratory technique

Assisted coughing and huffing

Others (please specify)

- Approximate overall treatment duration spent for one patient

- Number of physiotherapists working together

Physiotherapists whose assistance you take

if no specify)

- Do you perform head down postural drainage in ventilated patients $\mathrm{Y} / \mathrm{N}$

- Decision making in choosing treatment techniques.

Decided personally

Decided by discussing with doctors

Decided by discussing with nurses

Decided by discussing with others (please specify)

- Number of sessions per day

Once a day

Twice a day

More than twice please specify the exact number

Decided according to patients needs

- What pre and post parameters assessed or checked (Please specify)

- Are you involved in setting initial ventilator parameters Regularly / Often / Occasionally / Never

- Are you involved in weaning from mechanical ventilator Regularly / Often / Occasionally / Never

- Do you perform any of the following role in extubation Suction during extubation

Decision making in extubation

Others (please specify)

Source of Support: The Indian Association of Physiotherapists (IAP) Conflict of Interest: None declared.
Your posting schedule in ICU

On rotation from general wards

Permanent in ICU 